\title{
DIREITO E JURISPRUDENCIA
}

\section{DOUTRINA}

\section{Necessidade e Utilidade Pública}

\author{
Hésio Fernandes Pinheiro \\ (Advogado no Distrito Federal)
}

$\mathrm{E}$

MBORA na prática do direito se apresentem com grande similitude os processamentos das desapropıiações por necessidade ou por utilidade pública; embora doutrinadores eméritos, com as boas razões que se verá, defendam a impropriedade do emprêgo simultâneo das duas expressões e, até mesmc, alguns legisladores tenham consagrado êsse ponto de vista em seus projétos, posteriormente transformados em leis, entendemos que tais vocábulos não se devem confundir.

A distinção, além de tradicional, mostra-se conveniente, devendo mesmo ser rigorosamente observada. O próprio Bielsa, em cuja opinião se apoiam tantos defensores do emprêgo da expressão única (utilidade), não deixa de reconhecer que:

"La diferencia es importante y, claro está, no solo desde el punto de vista teórico, sino prático; no se trata de una cuestión de terminologia." (1)

A natureza intrínseca do objeto e o gráu de urgência exigida pelo interêsse público, bem distinguem o útil do necessário. Se de cada fato concreto resuma a diferença, se as circunstâncias prátiças retratam e delineam as proviđências como necessárias ou simplesmente úteis, por que a confusão dos têrmos?

Em verdade a utilidade não se mistura com a necessidade e, por isso mesmo, não podem nem devem ser empregadas as expressões como equivalentes; muito menos, a primeira deve ser usada para abranger o conceito da segunda. E indubitável que necessidade apresenta um sentido bem mais restrito que a utilidade, pois nem tudo o que é útil se pode considerar necessário, enquanto que, o que necessário fôr, sem dúvida alguma, também útil será. Daí justificarem os que se filiam à corrente do emprêgo da expressão única, como, v. gr., o faz SEABRA FAGUNDES:

"O conceito de utilidade pública é em si tão amplo que a menção apenas dessa causa bastaria a autorizar a incorporação ao patrimônio estatal da propriedade privada, tanto quanto fôsse útil

1947 - pág. 441 . 
fazê-lo, como quando tal se figurasse necessário ou de interêsse social. A utilidade não implica necessàriamente necessidade ou interêsse social (em sentido estrito); mas o procedimento que fôr de necessidade pública ou de interêsse social será, forçosamente, de utilidade pública". (2)

ou por outras palavras, ainda no dizer do mesmo autor:

"A utilidade tem sentido mais ampla, abrange, quer o interêsse social quer a necessidade, e portanto, desde que é dada como motivo capaz de autorizar o direito de expropriação, dispensável seria a menção dessas outras causas." (3)

ou Carlos maximiliano:

"Andam, pois, com acêrto os escritores que usam de uma só expressão, genérica, ampla desapropriação por utilidade pública. A utilidade é compreensiva da necessidade como bem acentuou em oportuno aparte, por mim aplaudido, o estudioso Deputado Pereira Lira." (4)

ou Viveiros de Castro:

"O legislador constituinte teria feito melhor empregando sòmente a expressão utilidade pública, que é suficientemente compreensivel para abraçar todos os casos de necessidade pública." (5)

ou, ainda, SolidônIo LEITE quando diz:

"Não se pode fazer bem a distinção entre necessidade e utilidade pública, discriminando os serviços de uma e de outra ordem: os necessários à defesa e conservação do Estado e da sociedade, e os que têm por fim o progressivo desenvolvimento das fôrças sociais e o bem estar comum." (6)

Não obstante, distingue-se claramente a necessidade de ordem pública da utilidade, pelo evidente interêsse da primeira para a coletividade e, mais, por trazer em seu conceito uma certa urgência na resolução dos casos concretos que se apresentam.

(2) Seabra Fagundes - "Rev. Forense" - Vol. CXX - 1948 - pág. 5 - 3.

(3) Seabra Fagundes - O Contrôle dos Atos Administrativos pelo Poder Judi-t ciário - 2. ${ }^{2}$ Edição - pág. 410.

(4) Carlos Maximiliano - Discurso in Annaes da Assembléia Nacional Constituinte - Vol. XIV - I.N. - 1936 - pág. 135.

(5) Viveiros de CASTro - Tratado de Ciência da Administração e Direito Administrativo - 3. ${ }^{\mathrm{a}} \mathrm{Ed}$. - pág. 382 .

(6) A. Solidomio LeITE - Desapropriação por utilidade pública - 3.a Ed. Rio - 1928 - pág. 43 - n. ${ }^{\circ} 15$. 
Os eventuais exemplos do set verdadeiramente preciso ressumam dessas simples razões.

Ademais, a pura denominação de utilidade torna-se inexpressiva em certas ocasiões como, por exemplo, nas calamidades públicas. As providências, os auxílios, os socorros ou as desapropriações, em tais casos, não se mostram simplesmente úteis, são mais do que isso, são mui necessários, prementes e imprescindiveis mesmo. Em tais casos, a necessidade releva, mostrando sua importância sôbre o útil e, mais, a impropriedade de considerar-se tão sòmente útil uma providência de tal natureza.

Muito embora, como bem anota Carlos Medeiros Silva, "a significação juridica das palavras empregadas na Constituição se deve procurar antes nos textos das leis ordinárias, do que nos léxicos" (7), não entendemos, data venia, que se deva desprezar a noção de que os vocábulos útil e necessário não se mesclam.

De fato, se recorrermos aos glosários veremos, v.grr. que:

Lello Universal - Novo Dicionário Enciclopédico Luso-Brasileiro. Vol. II - Conceitua:

Necessário - adj. (lat. necessarius). De que se tem absoluta necessidade, indispensável: o ar é necessário à vida. Que acontece infalivelmente; fatal: o calor é o efeito necessário do fogo. Que não pode deixar de ser; as verdades necessárias da razão; o necessário opõe-se ao contingente. Muito útil, tornar-se necessário. S. M. O que é indispensável para a vida: falta-lhe o necessário - Ant. Supérfluo, inútil.

Util - adj. (lat. utilis). Que pode ter algum uso ou que serve para alguma coisa: animais úteis. Vantajoso, proveitoso, etc.

1813. diz:

ANTôNIo DE MORAIS Silva (Dicionário da Língua Portuǵuesa). Lisboa

Necessário - adj. Não voluntário, nem espontâneo. O que não pode deixar de ser; o que não pode ser de outro modo; opõe-se a contingente. $\mathrm{O}$ que é indispensável: v.g. o movimento do coração é necessário; a existência de Deus é necessária; o alimento é necessário para a vida."

Util — adj. - Que tem algum uso, serviço, préstimo para algum fim.

Domingos Vieira (Grande Dicionário Português, ou Thesouro da Línsua Portuguesa - Pôrto, 1873), informa:

Necessário - adj. (do latim necessarius). Que não pode deixar de ser, que não pode ser de outro modo; indispensável. coisa."

Util - adj. 2 gen. (do latim utilis). Que serve para alguma

(7) Parecer de Carlos Medeiros DA Silva - Consultor Geral da República sôbre - assunto - publicado no "D.O." de 15-5-1953 - págs. 8926-8928. 
No campo do direito as duas expressões têm significados próprios, mostrando-se também perfeitamente diferençadas, conforme observa SEABRA FAGUNDES:

"Existe necessidade pública se a Administração está diante de um problema inadiável e premente, isto é, que não pode ser removido nem procrastinado, e para cuja solução é indispensável incorporar no domínio do Estado o bem particular. Há utilidade pública quando a utilização da propriedade privada é conveniente e vantajosa ao interêsse coletivo, mas não constitui um imperativo irremovível." (8)

Ncsso Código Civil, com incontestáveis felicidade e acêrto, pois, distinguiu os vocábulos no art. 590, e, ao comentá-lo, Clóvis BEviláQua observa:

"Censuram alguns autores o sistema do direito pátrio que distingue duas ordens de causas que autorizam a desapropriação: a necessidade e a utilidade pública.

Não há, realmente, diferença alguma, quer de efeito quer de processos, entre a desapropriação por necessidade pública e a desapropriação por utilidade geral. Todavia é incontestável que os casos mencionados como de necessidade apresentam um caráter de maior gravidade e urgência do que os de utilidade e esta consideração justifica a distinção tradicional do direito pátrio." (9)

E vale a pena perscrutar essa "tradição".

A fim de limitar os freqüentes abusos que, na época, se verificavam contra a propriedade particular, a "Dèclaration des Droits de l'Homme et du Citoyen", em seu item XVII, estabeleceu:

"La propriété etant un droit inviolable et sacré, nul ne peut en être privé, si ce n'est lor que la necessité public, legalement constaté, l'exige evidement et sous la condition d'une juste e préalable indemnité."

O princípio foi consagrado na Constituição Francêsa de 3 de setembro de 1791 (Tit. O. Ab. 4):

"La propriété etant un droit inviolable et sacré, nul ne peut juste et préalable indemnité de celes dont la necessité publique légalement constatée, exigerait le sacrifice. (10)

Como se vê, havia de ocorrer vera necessidade e constatada legalmente para que se desse a desapropriação. A simples utilidade não bastava, não era suficiente.

(8) Seabra Fagundes - O Contrôle dos Atos Administrativos - Ed. 1941 pág. 272-73.

(9) Clovis Bevilaqua - Código Civil Comentado - Vol. III - Rio, 1917 pág. $122-123$ - Nota 4 .

(10) Cit. p. BarthelemY - Droit Public - Paris, 1937 pág. 248. 
Ao ser porém transplantado para o Código Napoleônico, o foi sob forma diversa. Leia-se o art. 545 e nêle está o rigorismo da necessidade amenizado com a sua substituição pelo vocábulo utilidade que, sem dúvida alguma, atende melhor, e sem obstáculos, às conveniências e aos interêsses do Estado.

"Nul ne peut être contraint de céder sa propriété - (reza o art. 545 do Código citado) - si ce n'est pour cause d'utilité public, et moyennant une juste et preàlable indemnité."

Procurando explicar o só vocábulo utilidade e o seu significado prático, diz E. Costa:

... la ley al requerir sólo la utilidad y no la necesidad ha dado el primer paso en el sentido de facilitar la expropriacion de la propriedad particular a las conveniencias publicas. Pero que deve entenderse por utilidad publica? He ahí la primera dificultad. Las exigencias, los gustos, las tendencias de la sociedade, en nuestros dias, son tan múltiples y variados que es imposible definirlas. En una población que carece de escuelas, por ejemplo, la construcción de un teatro sería fuera de propósito; pero dejaría de serlo en una ciudad rica y populosa, que necesita distracciones y atrae la concurrencia de estranjeros. Una plaza de toros sería una bominación en Inglaterra y um motivo de felicitaciones en España." (11)

Quando a Constituição Brasileira do Império, em seu art. 178, item 22, garantiu o direito de propriedade em tôda a sua plenitude, deixou previsto que:

"Se o bem público, legalmente verificado, exigir o uso e emprêgo da propriedade do cidadão, será êle prèviamente indenizado do valor dela."

acrescentando que:

"A lei marcará os casos em que terá lugar esta última excepção e dará as regras para se determinar a indenização."

não se referiu, expressamente, nem à necessidade nem à utilidade, muito embora, em pontos outros e de salpico, empregue a expressão utilidade pública. (V., por exemplo, art. 178 n. 2 , § 16, etc.).

Atendendo, porém, ao preceito constitucional citado, a Lei de 9 de setembro de 1826 regulou a matéria e, na sua ementa, consignou:

"Marca os casos em que terá lugar a desapropriação da propriedade particular por necessidade e utilidade pública, e as formalidades que devem preceder à mesma desapropriação."

(11) E. Costa - in Fallos de la Corte Suprema - Vol. XXXIII - pág. 162 - cit. por BIELSA - Derecho Administrativo - 4. ${ }^{2}$ Ed. Buenos Aires - 1947 - Nota a pág. 442 . 
Em seu texto, distingue as duas hipóteses autorizando, taxativamente, o uso ou emprêgo da propriedade particular por necessidade, em casos de: defesa do Estado, segurança pública, socorro público em tempo de fome ou outra extraordinária calamidade, ou de salubridade pública (art. $10^{\circ}$ ); e o mesmo uso ou emprêgo, porém por utilidade, para os fins de: instituições de caridade, fundações de casas de instrução de mocidade, comodidade geral, ou de decoração pública (art. $2 .^{\circ}$ ).

Essa dicotomia, hoje combatida por nomes respeitáveis, tem sua razão de ser e está ela na forma pela qual eram, então, processados os casos de necessidade e de utilidade. A iniciativa dos primeiros cabia ao Procurador da Fazenda Pública que depois de verificar a necessidade dirigia um requerimento ao Juiz do domicílio do proprietário, sendo êste ouvido; os segundos dependiam de ato do Corpo Legislativo, que verificavam a utilidade face a requisição do Procurador da Fazenda Pública, já instruída com a resposta do proprietário. (V. art. $30^{\circ}$ da cit. Lei).

Posteriormente, o Ato Adicional, em seu art. 10, ítem $3 .^{\circ}$, usou a expressão utilidade tão sòmente, e o fêz pela forma seguinte:

"Art. 10. Compete às mesmas Assembléias legislar:

3. ) Sôbre os casos e a forma por que pode ter lugar a desapropriação por utilidade municipal ou provincial."

Em 1845, pelo Decreto n..$^{353}$, de 12 de julho, foram, mais uma vez, previstos os "casos em que terá lugar a desapropriação por utilidade pública geral ou municipal da Côrte", e assim indicados:

"Art. 1." A desapropriação por utilidade pública geral, ou municipal da Côrte, terá lugar nos seguintes casos:

$\S$ 1. $^{\circ}$ Construção de edifícios e estabelecimentos públicos de qualquer natureza que sejam.

$\S 2 .^{\circ}$ Fundação de povoações, hospitais e casas de caridade ou de instrução.

$\S 3 .^{\circ}$ Aberturas, alargamentos ou prolongamentos de estradas, ruas, praças e canais.

$\S 4^{\circ}$ Construção de pontes, fontes, aquedutos, portos, diques, cais, pastagens, e dè quaisquer estabelecimentos destinados à comodidade, ou servidão pública.

$\S 5^{\circ}$ Construção ou obras destinadas à decoração ou salubridade pública."

Convém observar que essa lei, cuidando apenas da utilidade pública, não desprezou entretanto as hipóteses de necessidade, ressalvando em seu art. 35 que:

"Fica em seu vigor a Lei de vinte e nove (12) de setembro de mil oitocentos e vinte e seis, no que toca à desapropriação por necessidade."

(12) Há erro de referência. A Lei é de 9-9-1826 e não de 29-9-1826. 
Respeitada foi, portanto, a fórmula dual.

O Regulamento baixado com o Decreto n. ${ }^{\circ} 8.820$, de 30-12-1882, para execução da Lei n. ${ }^{\circ}$ 3.129, de 14-10-1882 (sôbre patentes de invenção), refere-se também a utilidade e necessidade, no art. 20, dizendo:

"Art. 20 - Se a necessidade ou utilidade pública exigir a vulgarização da invenção, ou o seu uso exclusivo pelo Estado, poderá, a patente ser desapropriada de conformidade com a legislação em vigor."

Em 1890, o Decreto Legislativo n. ${ }^{\circ} 602$, de 24 de julho, estabeleceu o processo para as desapropriações por utilidade Municipal na Capital Federal. Derrogando o Decreto $\mathrm{n}^{\circ} 353$, de $12-7-1845$, na parte concernente à desapropriação por utilidade pública municipal, não atingiu, entretanto, os casos de necessidade.

Logo depois, a Lei n. ${ }^{\circ} 85$, de 21-9-1892, dispondo sôbre a organização municipal do Distrito Federal, mandou estender, o processo adotado pelo Govêrno Federal nas desapropriações por utilidade pública, à Municipalidade (art. 54).

A Constituição Republicana de 1891, reproduzindo o preceituado no art. 72, § 18 da Constituição Provisória aprovada pelo Decreto $\mathrm{n}^{\circ} 510$, de 22 de junho de 1890 , em seu art. 72 , $\S 17$, e o Decreto n. ${ }^{\circ}$ 914-A, de 23-10-1890 (art. $72 \S 18$ ) adotaram as duas expressões ao consignar que:

"O direito de propriedade mantem-se em tôda a sua plenitude, salvo a desapropriação por necessidade, ou utilidade pública, mediante indenização prévia."

Esta redação sofreu acréscimo de duas letras pela reforma de 1926 ( 7 de setembro), sem que, entretanto, se alterasse a forma dicotoma do artigo.

Em 1903, a Lei n. ${ }^{\circ} 1.021$, de 26 de agôsto mandou aplicar a tôdas as obras da competência da União e do Distrito Federal o Decreto n. ${ }^{\circ} 816$, de 10 de julho de 1855 (13) já referido, no qual introduziu algumas modificações.

Pouco depois, entretanto, veio o Decreto n..$^{\circ} 4.956$, de 9 de setembro de 1903, que aprovando "o regulamento de consolidação e modificação do processo sôbre as desapropriações por necessidade ou utilidade pública". Bem diferençou os casos de necessidade dos de utilidade ao dispôr:

"Art. 1. $0^{\circ}$ A desapropriação só pode ter lugar por necessidade ou utilidade pública, legalmente verificada, como excepção única à plenitude do direito de propriedade na forma do art. $72 \S 17$ da Constituição Federal.

(13) Regulamentada sua execução pelo Decreto n..$^{\circ} 1.664$, de 27-10-1855. Este, por sua vez, foi mandado aplicar às desapropriaçóes de águas para abastecimento da população pelos arts. 21 a 25 da Lei n. ${ }^{\circ} 3.396$, de 24 de novembro de 1882 . 
Art. 2..$^{\circ}$ A desapropriação por necessidade pública verificase nos seguintes casos (Lei de 9 de setembro de 1926, art. 1. ${ }^{\circ}$, Decreto n. 353 , de 12-7-1845, art. 35):

$1^{\circ}{ }^{\circ}$ ) Defesa do Estado;

2. ${ }^{\circ}$ ) Segurança Pública;

$3 .^{\circ}$ ) Socorro Público em temṕo de fome, ou outra extraordinária calamidade;

4. ${ }^{\circ}$ ) Salubridade pública.

Art. $3 .^{\circ}$ A desapropriação por utilidade pública verifica-se nos seguintes casos (Decreto n. ${ }^{\circ} 353$, de 1945 , art. $1 .^{\circ}$ ):

$1^{\circ}$ Construção de edifícios e estabelecimentos públicos de qualquer natureza que sejam;

$2 .^{\circ}$ ) Fundação de povoações, hospitais e casas de caridade ou de instrução;

3. ${ }^{\circ}$ ) Aberturas, alargamentos, ou prolongamentos de estradas, ruas, praças e canais;

$4 .^{\circ}$ ) Construção de pontes, fontes, aquedutos, portos, diques, cais, pastagens e de quaisquer estabelecimentos destinados à comodidade ou servidão pública.

$5^{\circ}$ ) Construções, ou obras destinadas à decoração ou salubridade pública."

Esse ato preceituou (arts. $4 .^{\circ}$ e $5 .^{\circ}$ ) as formas de processar os casos de necessidade e de utilidade pública, repetindo, com as devidas adaptações decorrentes da nova forma de Govêrno, as normas constantes do art. $3 .^{\circ}$ da Lei de 1826 (sôbre necessidade) e prevendo que, nos casos de utilidade, a verificação "terá lugar por ato do Congresso, ou do Presidente da República quanto às obras de competência da União, por ela executadas, ou por empresários, ou companhia, a quem for incumbida a sua execução. E por ato do Conselho, ou do Prefeito do Distrito Federal em relação às obras de utilidade pública do Município por êle projetadas e executadas administrativamente ou por contrato (Decreto 353 , de 1845 , arts. 2 e 11 e $\S 10^{\circ}$ e Lei n. $^{\circ} 1.021$, de $26-8-1903$, art. $\left.1^{\circ}\right) "$.

Em 1916, o Código Civil, mais uma vez, adotou a duplicidade de têrmos e, assim, lê-se no art. 590:

"Também se perde a propriedade imóvel mediante desapropriação por necessidade ou utilidade pública.

$\S 10^{\circ}$ Consideram-se casos de necessidade pública:

I - A defesa do território nacional.

II - A segurança pública.

III - Os socorros públicos, nos casos de calamidade.

IV - A salubridade pública. 
$\S 2 .^{\circ}$ Consideram-se casos de utilidade pública:

I - A fundação de povoações e de estabelecimentos de assistência, educação ou instrução pública.

II - A abertura, alargamento ou prolongamento de ruas, praças, canais, estradas de ferro e, em geral, de quaisquer vias públicas.

III - A construção de obras ou estabelecimentos destinados ao bem geral de uma localidade, sua decoração ou higiene.

IV - A exploração de minas."

A Constituição de 1943, em seu art. 113, item 17, dispunha:

" $E$ garantido o direito de propriedade, que não poderá ser exercido contra o interêsse social ou coletivo, e na forma que a lei determinar. A desapropriação por necessidade ou utilidade pública far-se-á nos têrmos da lei, mediante prévia e justa indenização. Em caso de perigo iminente, como guerra ou comoção intestina poderão as autoridades competentes usar da propriedade particular até onde o bem público o exija, ressalvado o direito à indenização ulterior."

A Carta de 1937 não quebrou a usança e, assim, vemos no ítem 14 do art. 122 grafado o seguinte:

"O direito de propriedade, salvo a despropriação por necessidade ou utilidade pública, mediante indenização prévia. O seu conteúdo e os seus limites serão definidos nas leis que lhe regularem o exercício."

Também agasalhou a distinção a Lei Constitucional $\mathrm{n} .^{\circ} 5$, de 10 de março de 1942, que alterou a redação do citado ítem dando-lhe a redação seguinte:

"O direito de propriedade, salvo a desapropriação por necessidade ou utilidade pública, mediante indenização prévia, ou a hipótese prevista no $\S 2 .^{\circ}$ do art. 166 . O seu conteúdo e os seus limites serão definidos nas leis que the regularem o exercício."

Com o advento do Decreto-lei n. ${ }^{\circ} 3.365$, de 21 de junho de 1941, foram englobados todos os casos que vinham sendo considerados como de utilidade ou de necessidade pública sob o título uno de utilidade. Dêsse modo, temos em vigor a seguinte relação indistinta:

Art. 5. Consideram-se casos de utilidade pública:

a) a segurança nacional

b) a defesa do Estado;

c) o socorro público em caso de calamidade; 
d) a salubridade pública;

e) a criação de melhoramento de centros de população, seu abastecimento regular de meios de subsistência;

f) o aproveitamento industrial das minas e das jazidas minerais, das águas e da energia hidráulica;

g) a assistência pública, as obras de higiêne e decoração, casas de saúde, clínicas, estações de clima e fontes medicinais;

h) a exploração ou a conservação dos serviços públicos;

i) a abertura, conservação e melhoramento de vias ou 1ogradouros públicos, a execução de planos de urbanização; o loteamento de terrenos edificados ou não para sua melhor utilização econômica, higiênica ou estética;

j) o funcionamento dos meios de transportes coletivos;

k) a preservação e conservação dos monumentos históricos e artísticos, isolados ou integrados em conjuntos urbanos ou rurais, bem como as medidas necessárias a manterlhes a realçar-lhes os aspectos mais valiosos ou característicos e, ainda, a proteção de paisagens e locais particularmente dotados pela natureza;

1) a preservação e a conservação adequada de arquivos, documentos e outros bens móveis de valor histórico ou artístico;

m) a construção de edifícios públicos, monumentos comemorativos e cemitérios;

n) a criação de estádios, aeródromos ou campos de pouso para aeronaves;

o) a reedição ou divulgação de obra ou invento de natureza científica, artística ou literária;

p) os demais casos previstos por leis especiais.

E as razões da inovação encontram-se assim justificadas na Exposição de Motivos que acompanhou o projeto:

"Enumera, em seguida, o projeto os casos de utilidade pública abandonando a distinção entre "necessidade" e "utilidade" que, remontando à lei de 9 de setembro de 1826, vem sendo repetida nas posteriores sem que corresponda entretanto a qualquer objetivo de ordem técnica ou prática, porque idênticos são o processo de declaração e os efeitos da medida. A discriminação dos casos de utilidade pública é bem mais ampla do que a das leis vigentes."

A Constituição de 1946 em seu art. 141, § 16, dispos:

"E garantido o direito de propriedade salvo o caso de desapropriação por necessidade ou utilidade pública, ou por interêsse social, mediante prévia e justa indenização em dinheiro. Em caso 
de perigo iminente, como guerra ou comoção intestina, as autoridades competentes poderão usar da propriedade particular se assim o exigir o bem público, ficando, todavia, assegurado o direito a indenização ulterior."

Além da fórmula duplice e clássica, a nova Constituição ainda estabeleceu, sem ratificar a fusão adotada pela legislação ordinária, uma terceira forma de desapropriação: - por interêsse social, devido à emenda de autoria do Senador FERREIRA DE SOuzA na Assembléia Constituinte. E justifica-a o autor dizendo:

"Que o homem possua como seu, de forma absoluta, aquêles bens necessários à sua vida, à sua profissão, à sua manutenção e à sua família, mesmo os que constituírem economias para o futuro, é perfeitamente lógico, mesmo de Direito Natural.

Mas, além dêsse mínimo, ou a propriedade tem uma função social, ou o seu proprietário a explora ou a mantém dando-lhe utilidade, concorrendo para o bem comum, para o enriquecimento geral, ou ela não se justifica. $\mathrm{Na}$ hipótese, a Emenda não chega ao extremo de negá-la. Mas superpondo o bem comum ao bem individual, admite a expropriação das propriedades inúteis, das que poderiam ser cultivadas e não o são daquelas cujo domínio absoluto chega a representar um acinte aos outros homens." (14)

Essa nova modalidade, posta na Constituição de 1946, foi acolhida com simpatia evidente pelos juristas nacionais, conforme se pode constatar, $v$. gr., pela leitura dos substanciosos trabalhos de CARLOS MEderRos Silva (in Rev. de Dir. Adm. - Vol. 29, fls. 1-15, de Seabra Fagundes (in-Rev. Forense Vol. 120, fls. 5), de WALdemar FerReira (in-Rev. Forense - Vol. 122, fls. 15), ou de PEDRo Calmon (in-Rev. Forense - Vol. 110. fls. 315), mas sôbre ela, aqui, não nos podemos deter sem fugir à diretriz destas notas. (15).

Em que pese o respeito devido às opiniões divergentes dos defensores da expressão única utilidade pública, preferimos acompanhar os clássicos que empregam, sempre, a forma dúplice: necessidade e utilidade. E é de se tomar nota que apesar da confusão legal dêstes vocábulos, estabelecida por vez primeira entre nós pelo Decreto-lei n. ${ }^{\circ} 3.365$, de 21-6-1941 a novidade não teve asilo na Constituição. (V. art. 141, § 16 da Const. de 1946).

Ainda, se buscarmos nos Anais da Assembléia Constituinte o que se falou sôbre o preceito, vamos encontrar, proferidas pelo Senador Ferreira de Souza, as seguintes palavras:

“... o ante-projeto só admitiu dois casos de desapropriação, os quais também vou chamar de clássicos: a desapropriação por

(14) Cit. p. Carlos Maximiliano - Com. à Const. Bras. - Vol. III - fls. 102/3. e transcrito in Parecer de Carlos Medeiros Silva, citado.

(15) Sôbre a desapropriação por interêsse social apresentamos, em 1954, no Instituto dos Advogados Brasileiros, uma inclinação para o estudo da matéria. - Publ. - Exp. Instituto - Jorn. Com. 5-6-1954. 
necessidade pública. As expressões necessidade e utilidade pública tem sentido fartamente conhecido por todos os Senadores Representantes, é absolutamente inalterável no campo do direito." (16)

Com elas, encerramos estes comentários não vendo como nem por que se manter a expressão única: - utilidade. A lei de desapropriações, vigorante, choca-se com o preceito Constitucional face a mescla dos vocábulos que adota. Está-se diante de um jus conditum, do qual não se pode fugir. Por outro lado, a terceira modalidade de desapropriação por interêsse social - impõe a alteração da legislação ordinária, requerendo para o assunto novas e especiais atenções.

Nessa ocasião, entendemos oportuno que ao se dispor sôbre a fórmula nova, também se aproveite para desassociar os casos de utilidade dos de necessidade; e, mais, que se tornem sumários os processos dêstes, mas que nos processos judiciais daquêles, se possibilite apreciar, discutir e decidir o mérito da desapropriação. social".

Tudo aconselha, ainda, que bem se demarquem as hipóteses de "interêsse

As três modalidades não se devem entrosar de leve sequer, pois se isso ocorrer, devido a inadvertências ou precipitações do legislador, teremos a forma nova entrelaçando-se com as duas outras (tradicionais) e a mostrar-se como tautologia nas instâncias judiciais.

Os riscos ressumariam daí, a doutrina e a jurisprudência formariam partidos, a fórmula Constitucional trifurcada perderia a virtude do seu propósito, dada a carência de efeitos práticos e de características processuais peculiares.

(16) CÂmara dos Deputados - Anais da Comissão de Constituição - Vol. III - Imp. Nac. 1948 - pág. 116. 